Supplementary Information for

\title{
Nanoparticle-embedded Polymer : In situ Synthesis, Free-standing Films with Highly Monodisperse Silver Nanoparticles and Optical Limiting
}

\author{
Shatabdi Porel, Shashi Singh, S. Sree Harsha, \\ D. Narayana Rao and T. P. Radhakrishnan*
}

\section{Contents}

Page 2 Details of synthesis, film fabrication, UV-Vis spectroscopy, scanning electron microscopy, transmission electron microscopy and electron diffraction

Page 3 Photograph of Ag-PVA and SEM image of Ag-PVA-PS

Page 4-5 UV-Vis absorption spectra of Ag-PVA [composition and heat treatment (time/temperature) variations]

Page 6-8 TEM images of Ag-PVA [composition and heat treatment (time/temperature) variations]

Page 9 Electron diffraction images

Page 10 Details of nonlinear absorption studies 


\section{Synthesis and film fabrication}

$5.3 \mathrm{mg}(3.12 \mathrm{mmol})$ or $8.1 \mathrm{mg}(4.8 \mathrm{mmol})$ or $10.8 \mathrm{mg}(6.4 \mathrm{mmol})$ of silver nitrate dissolved in 0.5 $\mathrm{ml}$ water was mixed with a solution of $120 \mathrm{mg}$ of polyvinyl alcohol, PVA (Fluka, average molecular weight $=15 \mathrm{kDa}, \%$ hydrolysis $=87-89)$ in $0.6 \mathrm{ml}$ water to prepare the three different compositions. The solution mixture was diluted by adding $2.0 \mathrm{ml}$ more of water and stirred for $10 \mathrm{~min}$ at room temperature $(27$ $30^{\circ} \mathrm{C}$ ). The solution was always protected from light. MilliQ purified water was used in all operations.

Glass/quartz plates were cleaned by sonication with isopropyl alcohol, methanol and finally acetone for $10 \mathrm{~min}$ each. A few drops of a solution of polystyrene, PS (average molecular weight $=280$ $\mathrm{kDa}$ ) in toluene ( $1 \mathrm{~g}$ in $8 \mathrm{ml}$ ) was spin coated on the glass substrate using a standard Photoresist Spinner at 1,000 RPM for $10 \mathrm{sec}$. Two such layers were coated in succession and the coated plate was air-dried. On top of the polystyrene coating, the silver nitrate - PVA solution was spin coated at 6,000 RPM for $10 \mathrm{sec}$. A second layer was coated similarly. Alternately, the silver nitrate - PVA alone was spin coated directly on quartz substrates without the polystyrene film.

The film coated plates were heated in a standard hot air oven for different times ranging from 5 $60 \mathrm{~min}$ and at temperatures ranging from $50-110^{\circ} \mathrm{C}$.

\section{Electronic absorption studies}

Electronic spectra of the Ag-PVA films coated on quartz substrates were recorded on a Shimadzu Model UV-3101 UV-Vis Spectrometer. The spectra were deconvoluted using Gaussian functions to extract the intensity, peak and line width of the plasmon absorption accurately.

\section{Scanning electron and transmission electron microscopy}

SEM of Ag-PVA/PS was recorded on a Philips XL 30 ESEM. The film was sandwiched between two glass plates and held vertically to examine the cross section. EDXS was used to confirm the nature of the layers. Samples for TEM were prepared as follows. Glass substrate with the Ag-PVA/PS coating was immersed in a layer of toluene in a petri dish. The Ag-PVA films floated to the toluene surface in about 5 min. The film was directly collected on 100 mesh folded copper grid. The samples were examined in a JEOL 100CX TEM at an accelerating voltage of $100 \mathrm{kV}$ using a $20 \mu \mathrm{m}$ aperture. Electron diffraction data was collected from the particles at $100 \mathrm{kV}$ accelerating voltage at a camera length of 46 or $76 \mathrm{~cm}$. The patterns were photographed using beam stoppers for $4 \mathrm{sec}$.

\section{Electron diffraction}

Electron diffraction data was collected from the particles at $100 \mathrm{kV}$ accelerating voltage at a camera length of 46 or $76 \mathrm{~cm}$. The patterns were photographed using beam stoppers for $4 \mathrm{sec}$. 


\section{Photograph of the free-standing Ag-PVA film}

Placed on a teflon sheet. The empty hole on the left shows the contrast.

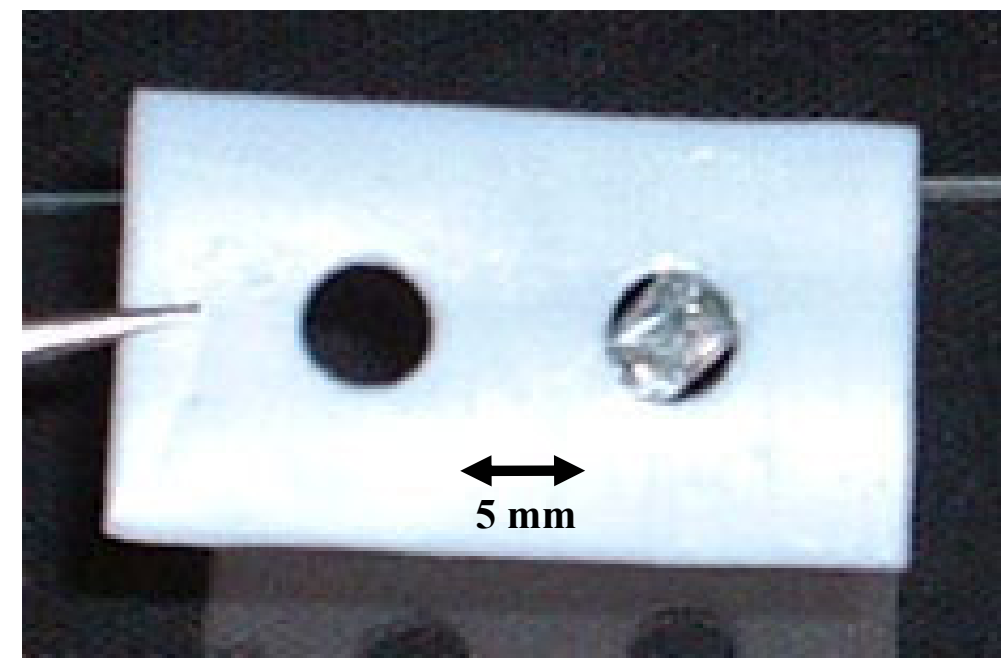

\section{SEM image of the Ag-PVA-PS film}

The film is placed between two glass plates and held vertically. EDXS was used to confirm the nature of the layers.

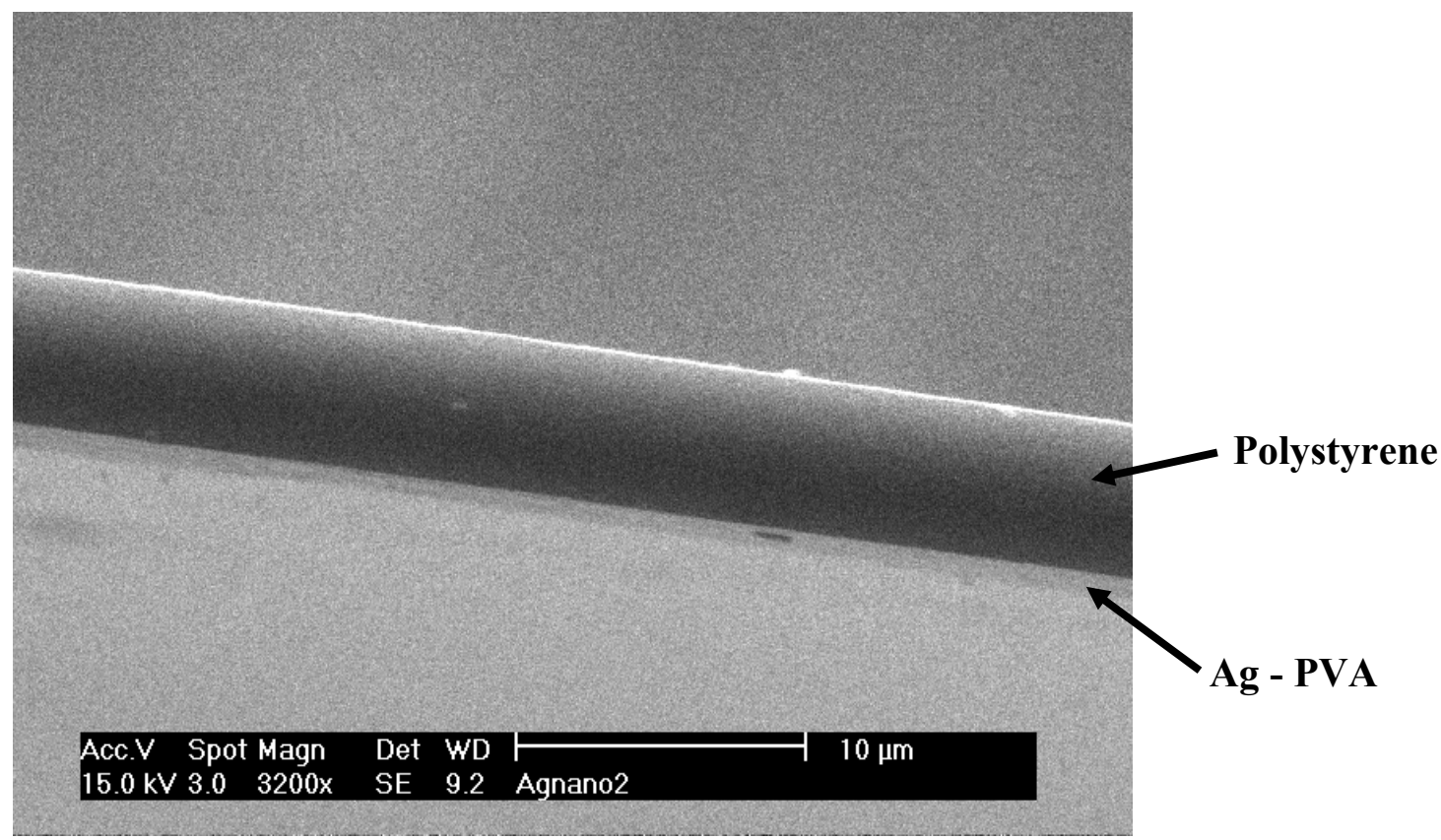




\section{UV-Vis Spectra of Ag-PVA}

\section{$\underline{\text { Time/composition variation study }}$}

(Heating temperature $=90^{\circ} \mathrm{C}$ )
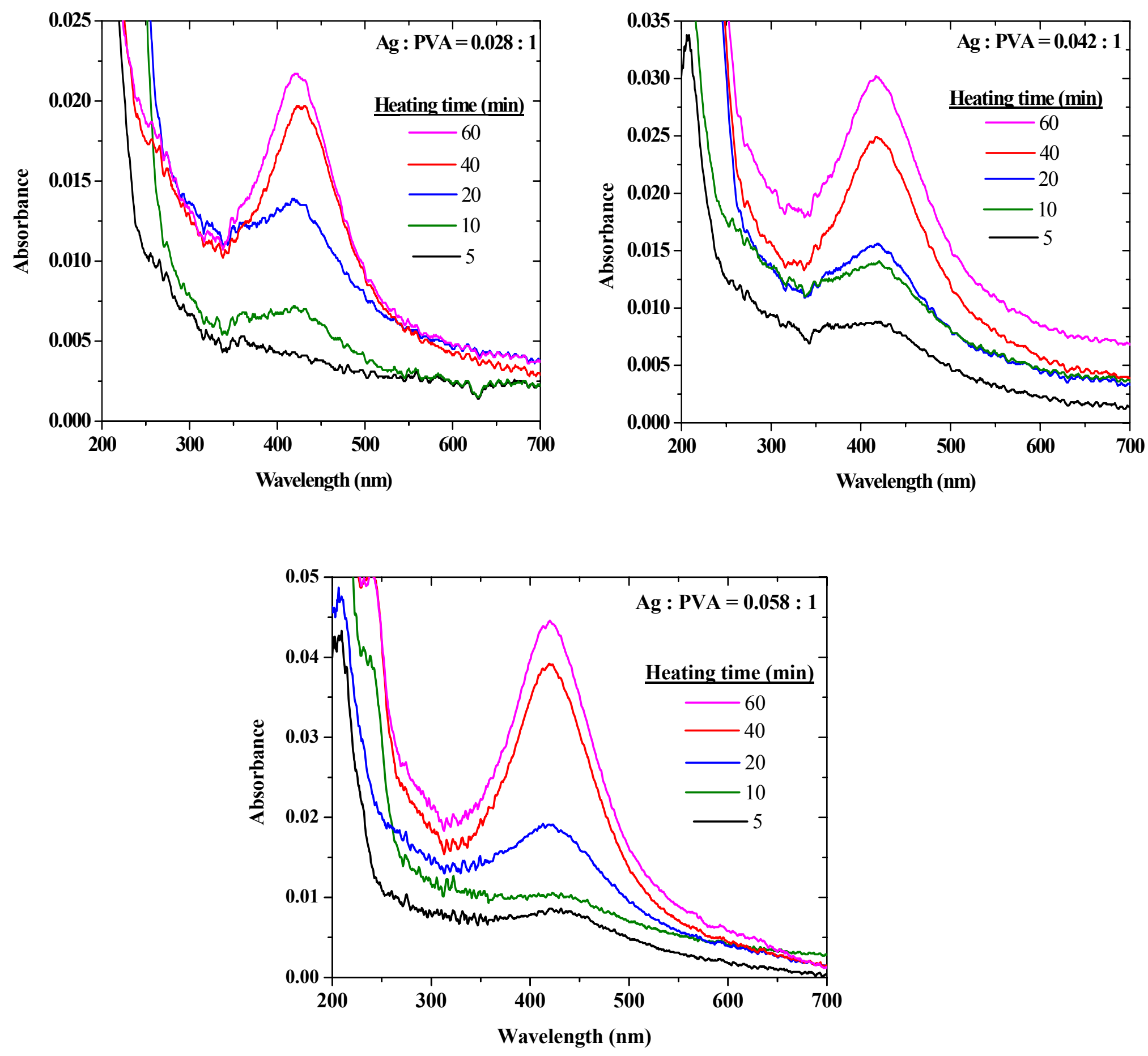


\section{$\underline{\text { Temperature/composition variation study }}$}

\section{(Heating time $=60 \mathrm{~min})$}
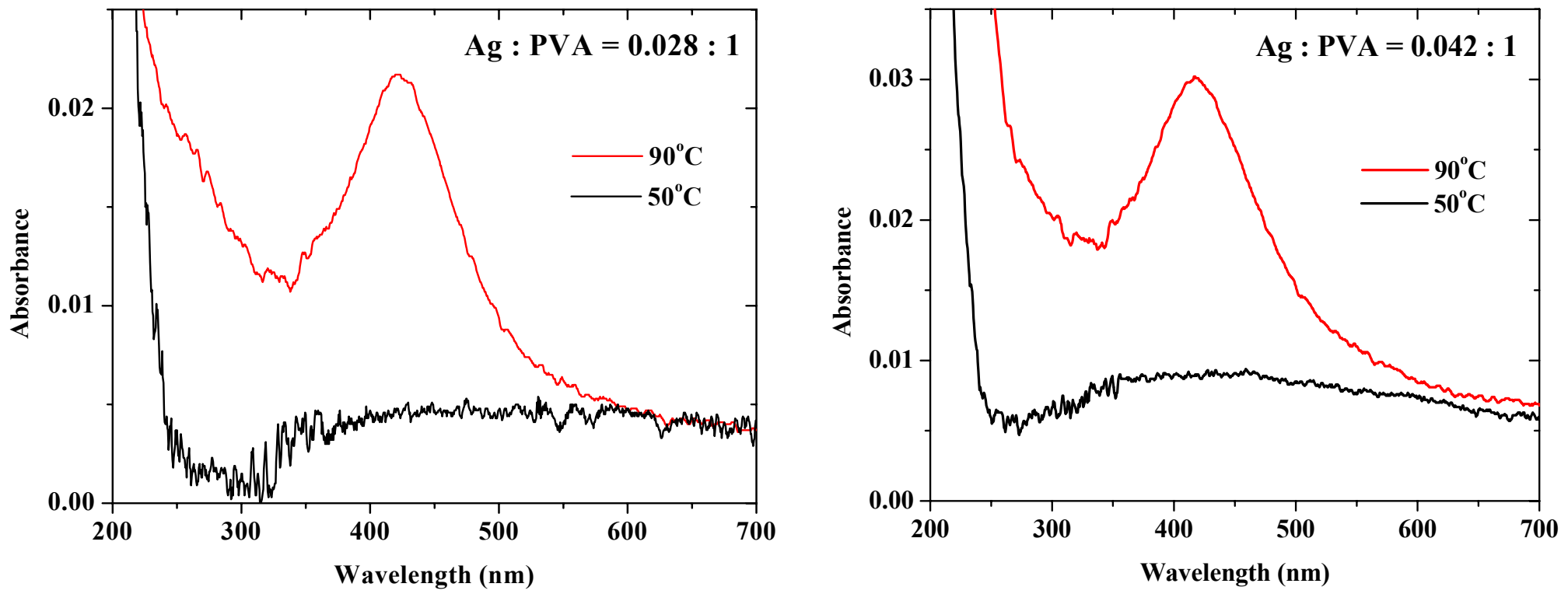


\section{TEM images of Ag-PVA}

\section{Time/composition variation study}

$\left(\right.$ Heating temperature $\left.=90^{\circ} \mathrm{C}\right)$

\section{Panels}

Left to right

- heating times

: 5, 10, 20, 40, $60 \mathrm{~min}$

Top to bottom

- Ag/PVA weight ratios

: $0.028,0.042,0.058$

Scale bar $=20 \mathrm{~nm}$
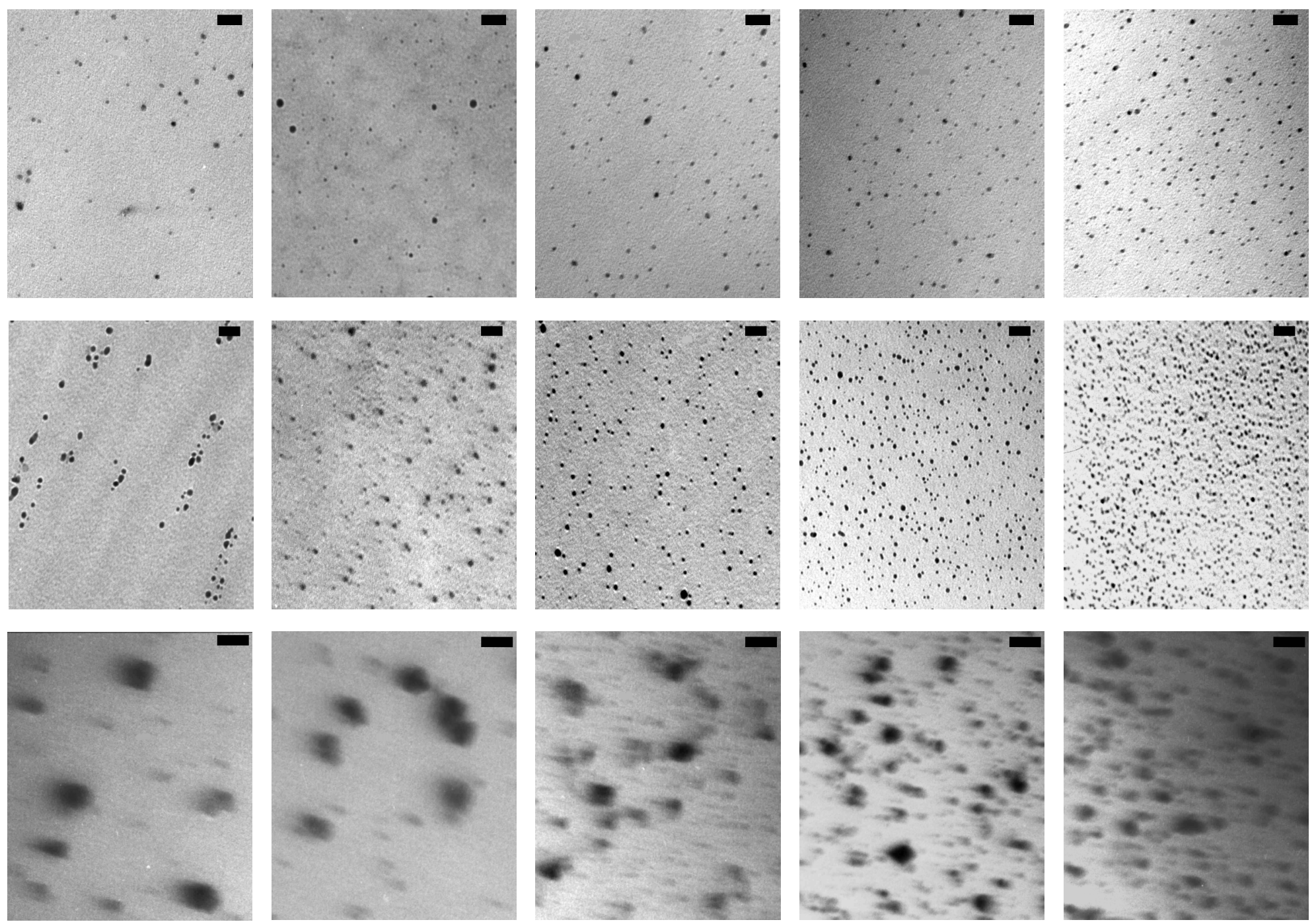


\section{Temperature/composition variation study}

$$
\text { (Heating time }=60 \mathrm{~min})
$$

\section{Panels}

Left to right

Top to bottom

Scale bar $=20 \mathrm{~nm}$

$$
\begin{array}{ll}
\text { - heating temperatures } & : 50,70,90,110^{\circ} \mathrm{C} \\
\text { - Ag/PVA weight ratios } & : 0.028,0.042,0.058
\end{array}
$$
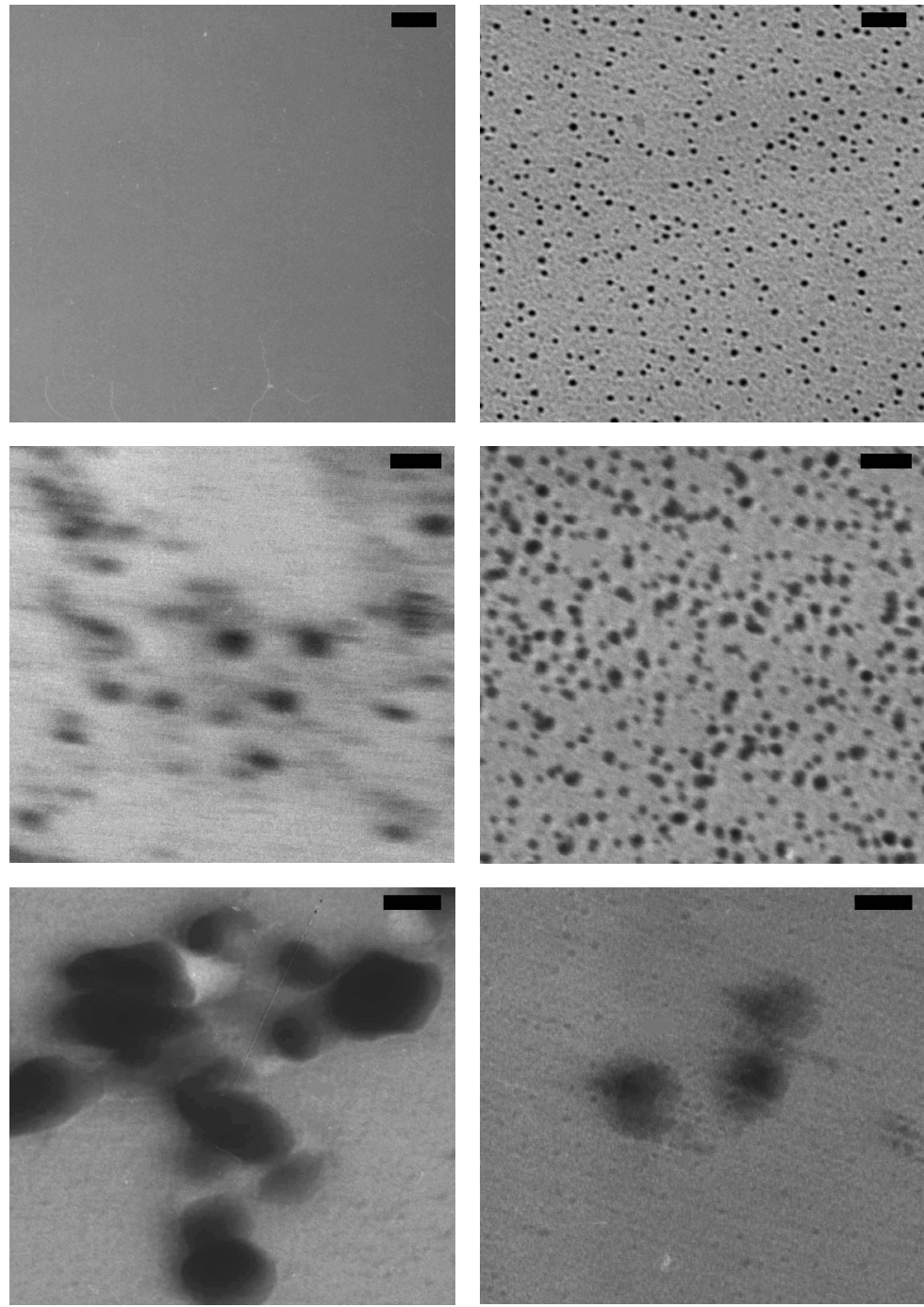
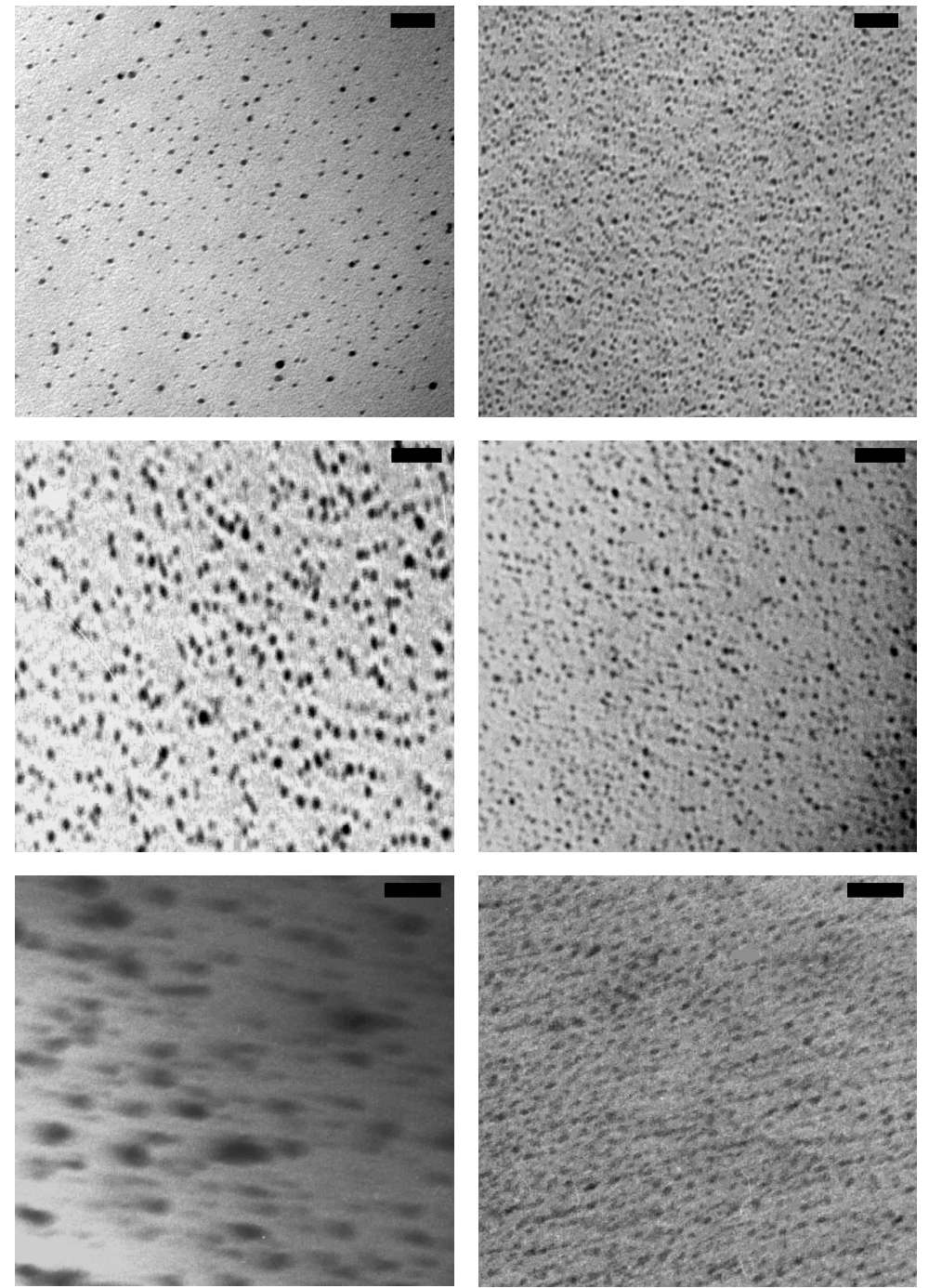


\section{$\underline{\text { Time/temperature variation study }}$}

$(\mathrm{Ag} / \mathrm{PVA}$ weight ratio $=\mathbf{0 . 0 4 2})$

\section{Panels}

Left to right

Top to bottom

Scale bar $=20 \mathrm{~nm}$

$$
\begin{array}{ll}
\text { - heating temperatures } & : 50,70,90,110^{\circ} \mathrm{C} \\
\text { - heating time } & : 10,60 \mathrm{~min}
\end{array}
$$
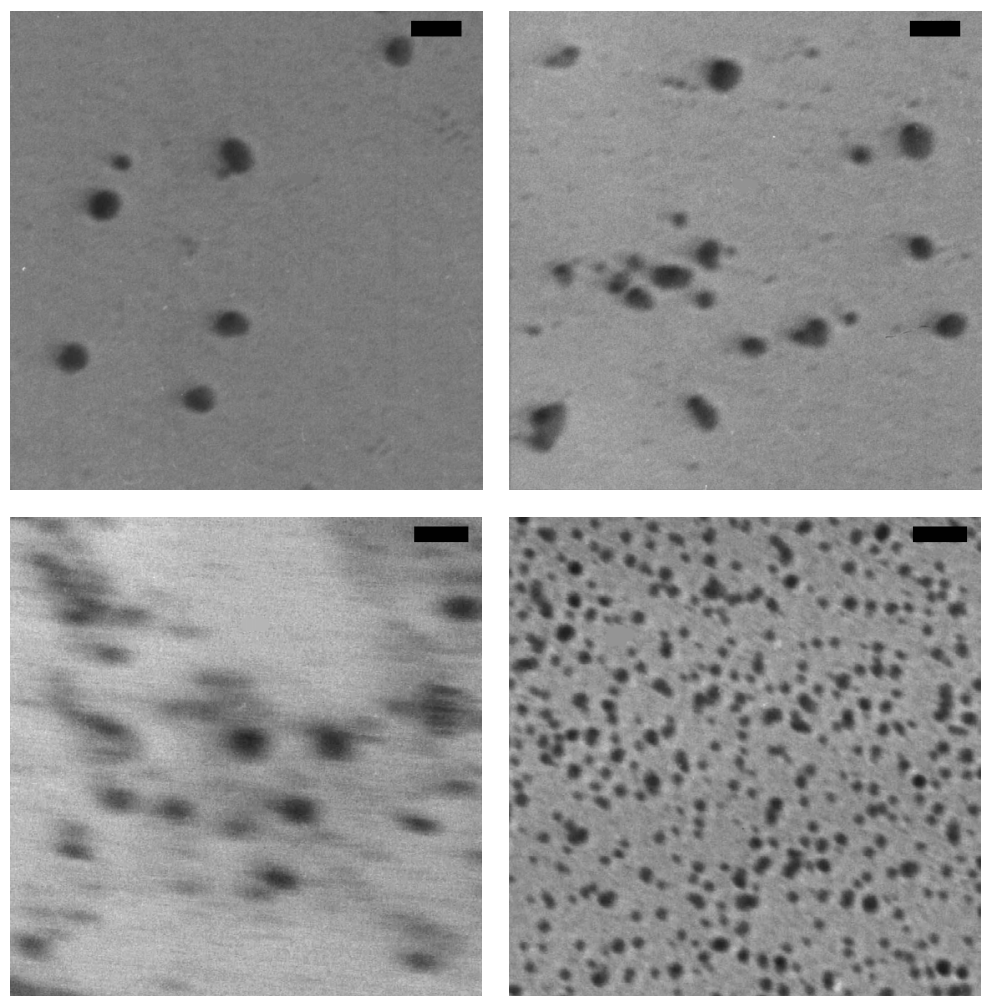
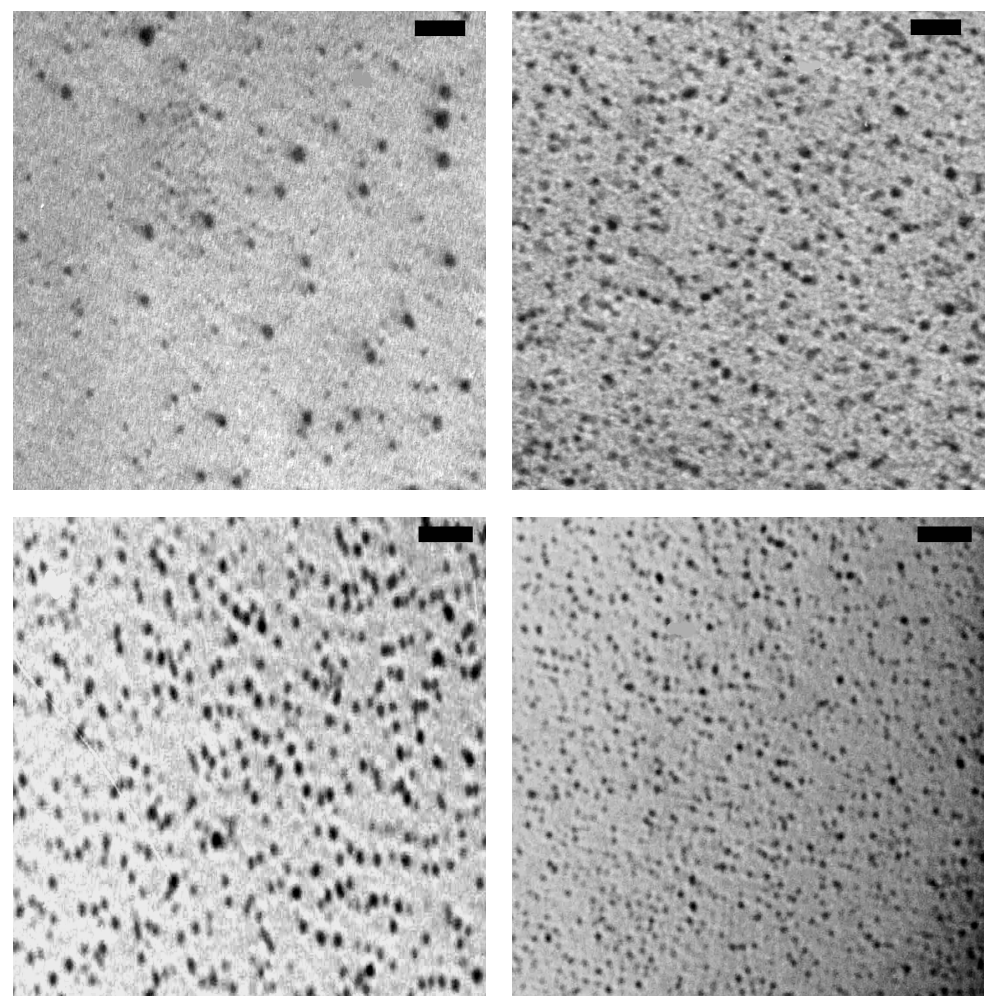


\section{Electron diffraction images of selected Ag-PVA films}
(a) $\mathrm{Ag}: \mathrm{PVA}=0.042: 1, \quad 110^{\circ} \mathrm{C}$,
$10 \mathrm{~min}$
(camera constant $=46 \mathrm{~cm})$
(b) $\mathrm{Ag}: \mathrm{PVA}=0.042: 1, \quad 110^{\circ} \mathrm{C}$,
$60 \mathrm{~min}$
(camera constant $=76 \mathrm{~cm}$ )
(c) $\mathrm{Ag}: \mathrm{PVA}=0.058: 1, \quad 90^{\circ} \mathrm{C}$,
$60 \mathrm{~min}$
$($ camera constant $=76 \mathrm{~cm})$

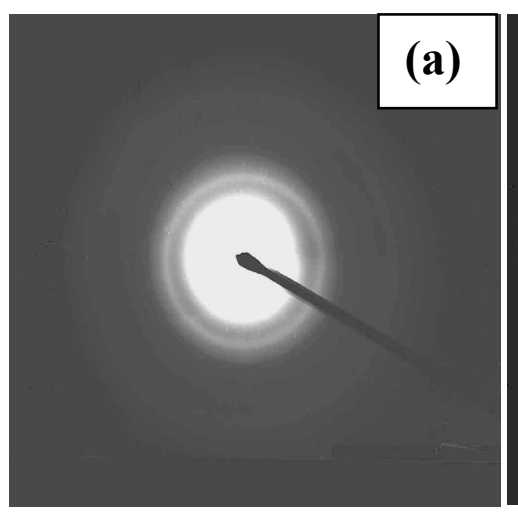

(b)

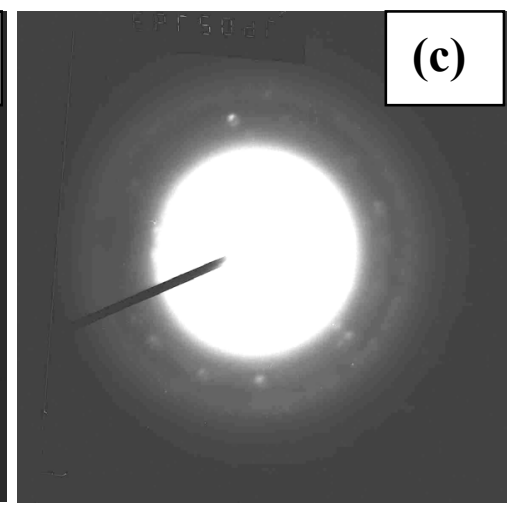




\section{Details of Nonlinear Absorption Studies}

Nonlinear absorption of silver nanoparticles in PVA matrix was studied using the open aperture Z-scan technique. The second harmonic beam (532 nm) of an Nd:YAG laser $(6 \mathrm{~ns}, 10 \mathrm{~Hz})$ was employed. Laser beam was focused on the sample using a lens of $60 \mathrm{~mm}$ focal length; the beam waist was $20 \mu \mathrm{m}$ at focus leading to peak intensities in the range $0.18-1.7 \mathrm{~J} \mathrm{~cm}^{-2}$ which could be varied using calibrated neutral density filters. The transmitted output was collected using a calibrated fast photodiode (FND 100) and processed using a data acquisition system consisting of a boxcar avarager, ADC and computer. The sample position was moved along the z-axis using a computer-controlled translation stage. The films were stable at all the intensities reported in the paper. The optical setup is shown in the following figure.

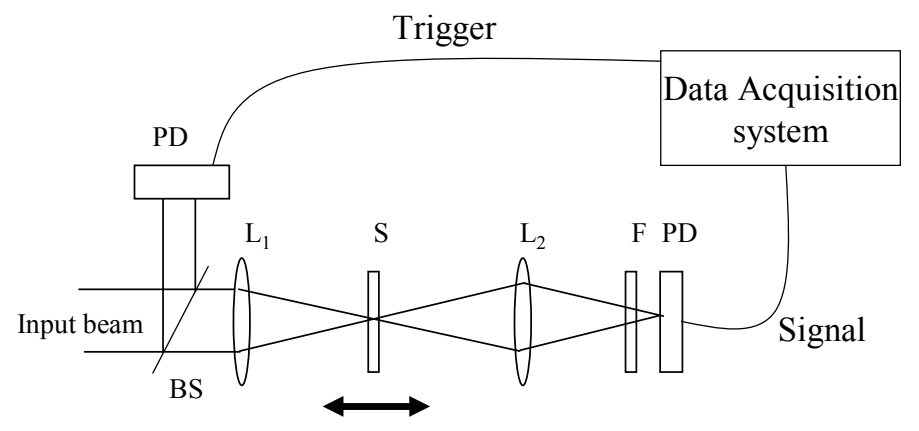

Z-scan setup: $L_{1}, L_{2}$ - lenses, $S$ - sample on translation stage, BS - beam splitter, F - neutral density filter, PD - photodiode

Optical limiting properties were studied keeping the sample at the focus in $f / 24$ geometry. The input energy was varied using calibrated neutral density filters and output was measured as noted above. The optical limiting curve was drawn as output fluence vs input fluence. Each experimental point is an average of 64 laser pulses. The limiting threshold $\left(\mathrm{I}_{1 / 2}\right)$ is defined as the input fluence at which the transmitted output fluence becomes half of the linear transmittance. Dynamic range is defined as the ratio of the damage threshold to the limiting threshold. 